\title{
Beyond binary thinking: Making sense of modernity as a historical phenomenon
}

[ B O O K R E V I E W ]

Alexander, Jeffrey, C (2013) The dark side of modernity. Cambridge: Polity Press.

ISBN 978-0-7456-4822-4 pbk. Pages viii + 187.

Jeffrey Alexander's The dark side of modernity is an attempt at making sense of the fact that "modernity" the Western quest for progress and reason and pursuit of perfection - went awry and all the questions that come with having to recognize that. Questions such as how to make sense of the persistence of evil, the relationship between good and evil, how to make sense of modernity and its meanings in the world today, and the place of social theory in helping us understand shifts in Western modernity.

In this review I consider the central arguments of Alexander's book in relation to the work of the Haitian anthropologist Michel-Rolph Trouillot, and specifically Trouillot's (2001) book chapter entitled Anthropology and the savage slot: The poetics and politics of otherness. I contrast Alexander's book against Trouillot's work as a way of: 1) illuminating how differently the authors conceptualize and conclude on the good / evil dichotomy; 2) showing how their divergence on the question of "postmodernity" has significant implications for making sense of what came before it (modernity) and for how they make sense of and see the world today; and 3) providing preliminary insight into how differently the authors harness social theory/ anthropology, theorizing, empirical work and analysis in making sense of a changing world.

\section{Safiyya Goga}

Department of Sociology \& Social Anthropology, University of Stellenbosch, Stellenbosch

\& Human Sciences

Research Council (HSRC), Pretoria 


\section{The making of the West and the making of modernity: Intertwined processes}

To begin with, Alexander's arguments are based on and in dichotomies - in making sense of world history he suggests that since the Enlightenment at least, world history is characterized by a "rational" and an "irrational" line, and that the former leads to "progress" while the latter is suggestive of an "apocalypse". Social theory has provided a bridge between progress and apocalypse. What characterizes modernity within this set-up? "[W]e must clarify what initially marked the West off from other civilizations, the modern West from earlier periods in its history, and the twentieth century from earlier Western modern societies. This distinguishing notion was 'progress' and the possibility of perfection it implied" (Alexander 2013: 5). Here lies the crux of Alexander's premise; that Western modernity is fundamentally about the pursuit of progress and perfection. The challenge according to Alexander is for theorists now to take seriously the fact that modernity has a "dark" side as well, and that "... inside the culture and structure of modernity, good and evil are intensely intertwined.... It is a dangerous delusion to think modernity can eliminate evil; new kinds of dangers are produced that challenge new kinds of good" (Alexander 2013: 4).

The early chapters which discuss the ideas of some the "great thinkers" - Weber, Simmel, Eisenstadt, Parsons - and how they made sense of the world, including of their disillusionments with it, provide us with snapshots of social theory and sensemaking without ever really placing their theories outside of modernity, without subjecting them, in other words, to an analysis from somewhere else; from somewhere other than where the theorists themselves are standing and considering the world. It feels in other words like a view from the inside, an insider's perspective that remains resolutely within the terms already given to make sense of modernity. This review critiques this approach and its effects.

For both authors (Alexander and Trouillot), modernity, what it implies, its contents and meanings are intertwined with "the West", with the historical and concrete making of the West. For Alexander, what sets Western modernity apart is the idea of progress and the pursuit of perfection. For Trouillot, the process through which the West constructed itself as the West is marked off from other civilizations and other historical periods by the dichotomy of "utopia" and the "savage", of "here" and "elsewhere", of "us" and "all the rest". The Renaissance - "that fictional rebirth through which Christendom became the West" (Trouillot 2001: 30) - began the process through which the West would set itself apart. Unlike was the case for "Greece and Rome, or that of the Islamic world, the West's vision of Order implied from its inception two complementary spaces, the here and the elsewhere, which premised one another and were conceived as inseparable" (Trouillot 2001: 32). Western modernity was premised on the construction of an Other. 


\section{The problem of modernity: The problem of evil?}

What follows from Alexander and Trouillot's differing conceptions of the construction of modernity are different conceptions of the problem(s) of modernity. For both, the problem is revealed as an empirical one. For Alexander the problem is that modernity has not eradicated evil and we have to now avoid the "dangerous delusion" that it ever could or can. For Trouillot, the problem is more nuanced and complicated. The dichotomous structure of modernity as he outlines it has all but collapsed empirically, and what we are left with is what he calls the "residual" category of "the savage" (the "savage slot"). Conceptualized thus, the "problem" (at least for those who want to preserve and salvage the core of modernity) is that the Other no longer exists empirically. The structure on which good/evil was based, and through which it made sense, no longer exists, and the resulting moral equivalence between "Christians and cannibals" (who are now "equally good" or "equally evil") is what characterizes and preoccupies a postmodern world. The problem really for Trouillot is what is reflected in the "postmodernist mood", which is a kind of jarring realization that all was not, and could not be, well with modernity.

In a sense Alexander almost exemplifies the postmodern mood in his capturing of the dark side of modernity, when he writes: "Modernity was conceived as an end point, the telos of a transition that allowed rationality, or at least rationalization; equality, or at least differentiation; freedom, or at least autonomy vis-a-vis the powers that be" (Alexander 2013: 148). However, modern society proved to be not just "progressive, benevolent, and competent, but primitive, malevolent, and irrational. ... Slavery and racial domination were fundamental to Western modernity ... The great thinkers were likewise insensitive to what Claude Levi Strauss (1974[1955]) called the original sin of modernity. North, South, East and West, modernity had obliterated the first peoples and, indeed, the vast majority of aboriginal individuals themselves" (Alexander 2013: 148).

Alexander's book may be read as an expression of a sense of loss, a desire to recognize the "great" things and "great" thinkers of Western modernity and yet a sombre reflection on the necessity of recognizing that Western civilization was built in ways that prevent an easy correlation of a good us and a bad them.

\section{Postmodernity}

The postmodern mood that Alexander seems to exemplify is elaborated by Trouillot as the steady (empirical) erosion of the West's conception of itself. He writes:

"As the walls crumbled - North and South and East and West - intellectuals developed languages of postdestruction. It is this mixture of negative intellectual surprise, this postmortem of the metanarratives, that situates the postmodernist mood as primarily Western and primarily petit bourgeois. ... The postmortem 
inherent in the postmodernist mood implies a previous 'world of universals' (Ross 1988a: xii-xiii). It implies a specific view of culture and of cultural change. It implies, at least in part, the Enlightenment and nineteenth-century Europe" (Trouillot 2001: 20-21 - emphases added).

Trouillot takes postmodernity seriously. Alexander emphatically does not, as he easily discusses and does away with it in his final chapter. For him, postmodernity is simply an inadequate answer to the problems of modernity. For Trouillot there is a both a postmodern mood and a postmodern empirical situation to contend with; the postmodern mood is marked by a significant disillusionment with the Enlightenment: "The dominant mood of postmodernism thus appears as a historically specific phenomenon, a reaction provoked by the revelation that the Enlightenment and its conflicting tributaries may have run their course" (Trouillot 2001: 21).

The postmodern situation on the other hand is the recognition that the world has changed empirically, and it has changed in ways that are both due to modernity but that have also produced a new empirical situation which we need to take seriously. A provocatively subtitled section (The fall of the house of reason) of Trouillot's (2001: 20) chapter starts with the following statement: "Whatever else postmodernism means, it remains inseparable from the acknowledgement of an ongoing collapse of metanarratives in a world where reason and reality have become fundamentally destabilized." And further on: "Thanks to modernity, the savage has changed, the West has changed, and the West knows that both have changed empirically" (Trouillot 2001: 35). And while there is significant resistance to these empirical shifts and their implications, it is a very different world we live in today, as Trouilot (2001: 35$)$ notes:

"To be sure, one could reinvent the savage, or create new savages within the West itself - solutions of this kind are increasingly appealing. The very notion of pristine savagery, however, is now awkward, irrespective of the savage-object. Lingering conditions of modernity make the notion a hard one to evoke in imagination, now that hordes of savages have joined the slums of the Third World, or touched the shores of the West. We are far from the days when five Eskimos caused an uproar in London. The primitive has become terrorist, refugee, freedom fighter, opium and coca grower, or parasite ..."

Does Alexander's book represent a morose acceptance that the world has changed and that the metanarratives and foundational thoughts on which Western modernity were built are rapidly collapsing? And yet, there seems to be an inability (unwillingness) to conceptualize this and make sense of it in ways that take us beyond generalized, ahistorical acknowledgements and assertions such as evil cannot be 
eradicated in the world, or "new kinds of dangers are produced that challenge new kinds of good" (Alexander 2013: 4). Trouillot however takes us beyond the existential assertion that "evil exists in the world", towards a more historicized conception of its meanings.

Alexander's book does seem to exemplify the sense of loss created by the revelation that all was not as it seemed. Seemingly unable to make sense of the world as it has shifted empirically today, he wants to fix what appears to him to be broken. The final chapter of Dark side of modernity is dedicated to espousing some of the ways in which the "strains" of modernity can be "repaired". Here Alexander switches to a normative mode and offers technical solutions to the strains of modernity as well as listing (in an uncritical and self-evident way) empirical "evidence" of triumphs over the strains produced by modernity. Modernity, he seems to want to say, can be salvaged "[w] hile frontally addressing the dangerous frictions at the core of contemporary life, theory needs also to eschew the apocalyptic sensibility that often undermines critical theory. Social theorists of the great transitions were right about one thing. Modernity can allow flexibility and adaptation. Perverse social arrangements can be monitored, occasionally prevented, and sometimes repaired. There are self-correcting capacities inside modernity that sometimes allow contemporary societies to get it right" (Alexander 2013: 150 - emphases added).

Alexander (2013: 149) is emphatic that "twentieth century societies sometimes got it right", and sees the role of social theory as providing answers as to how and why these triumphs occurred. For instance, "How did imperialism end? How were wars opposed and sometimes prevented? How were racism, anti-Semitism and sexism sometimes attacked and often destroyed? How were totalitarian dictatorships overthrown, and why?" (ibid). His message then, is, and can only be, a limited one: "The message of this book has been that contemporary social theory must absorb the lessons of failed modernity in order to conceptualize not only its light but also its dark side" (ibid), stuck in a game of equivocating on and score-keeping on the good and evil of modernity and on questions that are ultimately and critically limited and hamstrung: is modernity both good and evil? Is it better now than before or more evil now?

\section{Alexander, Trouillot and the role of social theory}

Unsurprisingly, for Alexander, postmodern thinking reflects only a "challenge" to the inadequacy of modern theories, a kind of unfortunate filler that has to grudgingly be acknowledged: "Because of the inadequacies of modern theory, in the late twentieth century postmodern challenges to classical and modern social theories emerged" (Alexander 2013: 149). However, Alexander feels the answers provided by 
postmodern theory were not satisfying, as they "[throw] the modernist baby out with the bathwater" mainly because of their ahistoricity, "thin" understanding of cultural process, and "insufficiently" developed institutional ideas (ibid).

Alexander's "pragmatism" (sifting the "good" from the "bad") comes at the cost of analytical value. It does not draw the links between past and present in ways that clearly show or argue for a particular way of making sense of modernity and the shifts that have happened since (postmodernity). It cannot demonstrate what modernity truly means today because it does not interrogate the making of modernity sufficiently (it speaks about the "structure" of modernity without elaborating what this structure might be and how it functions to produce order, meaning and power). It does not in other words provide us with an adequately conceptualized and analytical history of modernity, one that would explain genealogically where we find ourselves today (in an arguably postmodern period, and what precisely that might mean).

Trouillot's approach to postmodernity is radically different as for him it marks a crucial shift in the remaking of the world, and therefore a critical point from which to begin the process of looking back at modernity. This way of working backwards to make sense of modernity is in keeping with his fundamentally historical approach (Trouillot, 1995, 2000), an approach that insists on starting with struggles in the present, in order to make sense of how the past impinges on and informs it (Trouillot 2000). For Trouillot, postmodernism is precisely what helps reveal the nature of modernity.

For Trouillot, the postmodern world and the shifts it reflects, holds an inherent promise. For him we "... could well read postmodernism, or at the very least the postmodern situation, as a case for the specificity of otherness, for the destruction of the savage slot" (Trouillot 2001: 38 - emphases added). The implication of restoring the "specificity of otherness" seems to be a fundamentally equalizing one, one that unmutes first persons, restores to them their irreducibility and shows how various others are in fact also a part of the construction of the West:

"To claim the specificity of otherness is to suggest a residual of historical experience that always escapes universalisms exactly because history itself always involves irreducible subjects. It is to reserve a space for the subject - not the existential subject favored by the early Sartre and who keeps creeping back into the mea culpa, but the men and women who are the subjects of history. ... It is to acknowledge that this space of the historical subject is out of reach of all metanarratives [...] because metanarrative claims to universality necessarily imply the muting of first persons, singular or plural, deemed marginal. To say that otherness is always specific and historical is to reject this marginality. The Other cannot be encompassed by a residual category; there is no savage slot ..." (Trouillot 2001: 39). 
Far from wanting social theory to become trapped in forms of Third Worldism that simply reverse the terms of the "us and all of them" binary on which the West was built, and thereby become its mirror image, Trouillot sees its task as demonstrating that "There is no Other but multitudes of others who are all others for different reasons ..." (Trouillot 2001: 39).

Alexander wants us to recognize and pay homage to the ability of the great thinkers to see the positive and not to discard the good in modernity. Trouillot wants us to see opportunity in the present historical moment, to conceptualize and theorize differently, i.e. empirically and analytically in ways that counter the core of what modernity stood for - foundational thoughts, metanarratives and the preservation of an Other, of a "savage slot". In that sense Trouillot is harsher and yet offers more hope than Alexander that things can be different; he is more attendant to the history and historicity of "modernity" and ultimately less willing to preserve and salvage the past, calling instead for a break by social theorists/ anthropologists/ postmodernists and those who seek to preserve the "savage slot", morosely or otherwise.

\section{References}

Trouillot, M-R (1995) Silencing the past: Power and the production of history. Boston: Beacon Press.

Trouillot, M-R (2000) Abortive rituals: Historical apologies in the global era. Interventions,2(2), 171-186.

Trouillot, M-R (2001) Anthropology and the savage slot: The poetics and politics of otherness, in Fox, R G (ed) Recapturing Anthropology: Working in the present. New Mexico: School of American Research Press. 